\title{
Mutated NPM1 in combination with overexpression of Meis1 or Hoxa9 is not sufficient to induce acute myeloid leukemia
}

\author{
Hanna Grauers Wiktorin ${ }^{1}$, Tina Nilsson ${ }^{2}$, Ann Jansson ${ }^{2}$, Lars Palmqvist $2,3^{*+}+\left(10\right.$ and Anna Martner ${ }^{1 \dagger}$
}

\begin{abstract}
Background: Acute myeloid leukemia (AML) carrying nucleophosmin 1 (NPM1) mutations $\left(\mathrm{NPMC}^{+}\right.$) is regarded as a separate entity of myeloid neoplasms due to its distinct biological and clinical features. However, $\mathrm{NPMc}^{+}$alone displays low leukemogenic activity and cooperating events appear crucial for AML to develop. Dysregulation of homeobox genes, such as HOXA9 and MEIS1, is a common transcriptional signature of NPMC ${ }^{+}$AML. Furthermore, the pathogenic role for $\mathrm{NPMC}^{+}$in $\mathrm{AML}$ remains incompletely understood.

Aim: To elucidate if $\mathrm{NPMC}^{+}$collaborates with Meis1 or Hoxa9 in the evolvement of AML.

Methods: Murine bone marrow cells were genetically engineered to express mutated NPM1 variant A in combination with overexpression of Meis1 or Hoxa9. The capacity of the transduced cells to transform in vitro and to cause leukemia in vivo was then assessed.

Findings and conclusion: There was no synergy between $\mathrm{NPMc}^{+}$and Meis1 or Hoxa9 in causing leukemogenic transformation of murine bone marrow cells, or in inducing AML in a transplantation model. Hence, overexpression of Meis1 or Hoxa9 in combination with $\mathrm{NPMC}^{+}$expression was not sufficient to generate an NPMc ${ }^{+} \mathrm{AML}$ mouse model.
\end{abstract}

Keywords: Acute myeloid leukemia, NPM1, Meis1, Hoxa9

\section{Background}

Nucleophosmin (NPM1) is found mutated in about $30 \%$ of acute myeloid leukemia (AML) cases, making it one of the most commonly mutated genes in AML [1, 2]. Wildtype NPM1 has been ascribed many biological functions, including a role in the biogenesis of ribosomes, genomic stability and transport of small basic proteins to the nucleus [3]. The NPM1 mutations occurring in AML disrupts the nucleolar localization signal of NPM1 and generates a nuclear export signal in its place, resulting in aberrant cytoplasmic localization of mutated NPM1 $\left(\mathrm{NPMc}^{+}\right)$[4]. Since 2008, the World Health Organization regards AML with mutated NPM1 as a provisional AML entity due to its unique characteristics [5]. Despite the

\footnotetext{
*Correspondence: lars.palmqvist@clinchem.gu.se

${ }^{+}$Lars Palmqvist and Anna Martner shared senior co-authorship

2 Department of Clinical Chemistry, Sahlgrenska University Hospital,

Bruna Stråket 16, 41345 Gothenburg, Sweden

Full list of author information is available at the end of the article
}

recognition of mutated NPM1 as a founder genetic lesion [6] and a putative target for novel therapy [7], the mechanism by which $\mathrm{NPMc}^{+}$contributes to leukemogenesis has only partly been explored. Animal models of NPMc ${ }^{+}$ AML, aiming at understanding the NPM1-driven leukemogenesis, have thus far revealed that $\mathrm{NPMc}^{+}$alone displays low leukemogenic activity $[8,9]$ and that additional cooperative mutations, such as FLT3-ITD [10] or N-ras mutations [9] are required for AML to develop.

Gene expression data from both NPM1-mutated adult and pediatric AML cases have identified an association between $\mathrm{NPMc}^{+}$and dysregulated expression of homeobox (HOX) and TALE genes, including Hoxa9 and Meis1, which are known to be involved in hematopoietic development [11-14]. In accordance, Ogawara et al. reported that $\mathrm{NPMc}^{+}$expression in $\mathrm{c}-\mathrm{Kit}^{+}$bone marrow (BM) cells results in increased expression of Hoxa9 [15]. Hoxa9 and Meis1 are primarily expressed at the level of hematopoietic stem and progenitor cells during normal 
hematopoiesis [16] and have been shown to cooperate in causing AML in transplantation mouse models $[17,18]$. The presumed $\mathrm{NPMc}^{+}$-induced Hoxa9 expression incited us to investigate a potential synergy between $\mathrm{NPMc}^{+}$and Meis1 in causing AML. To test this hypothesis, and in an attempt to develop a transplantation model reliant on $\mathrm{NPMc}^{+}$expression for in vivo onset of AML, C57BL/6 J bone marrow cells were transduced to express $\mathrm{NPMc}^{+}$ in combination with overexpression of either Meis1 or Hoxa9. However, we could not find any evidence for cooperation between $\mathrm{NPMc}^{+}$expression and Meis1 or Hoxa9 overexpression in leukemogenic transformation. Thus, our data show that overexpression of Meis1 or Hoxa9 is not sufficient to cause AML in combination with $\mathrm{NPMc}^{+}$in a murine bone marrow transplantation model.

\section{Methods}

\section{Retroviral vectors}

The following vectors have been previously described: MSCV-IRES-GFP (GFP virus) [19], MSCV-IRES-YFP (YFP virus) [20], MSCV-IRES-neo (neo virus) [21], MSCV-HA-Meis1a-IRES-YFP (Meis1 virus) [19], and MSCV-Hoxa9-IRES-neo (Hoxa9 virus) [21]. The sequence for the most common NPM1 mutation, mutation A, was purchased from Integrated DNA Technologies (Coralville, IA, USA), inserted into the MSCV-IRES-GFP vector and used to transiently transfect Phoenix Eco cells (ATCC, LGC Standards GmbH, Wesel, Germany). Virus-containing medium from Phoenix Eco was utilized to transduce GP + E86 cells (ATCC, LGC Standards GmbH, Wesel, Germany) and generate a stable $\mathrm{NPMc}^{+}$viral producer.

\section{Transduction of C57BL/6 J bone marrow cells}

All mice experiments were approved by the Animal Ethics Research Committee in Gothenburg. C57BL/6 J mice were obtained from Charles River Laboratories (Sulzfeld, Germany). Transduction of C57BL/6 J BM with viral vectors was performed as previously described [22]. In brief, murine BM cells harvested from C57BL/6 J mice 4 days after $150 \mu \mathrm{g} / \mathrm{g}$ 5-fluorouracil (5-FU, Accord Healthcare $\mathrm{AB}$, Solna, Sweden) treatment were transduced with $\mathrm{NPMc}^{+}$and neo or YFP viruses (NPMc ${ }^{+}$cells), Meis1 and GFP viruses (Meis1 cells), Hoxa9 and GFP viruses (Hoxa9 cells), Meis1 and NPMc ${ }^{+}$viruses (Meis1-NPMc ${ }^{+}$cells) or Hoxa9 and $\mathrm{NPMc}^{+}$viruses (Hoxa9-NPMc ${ }^{+}$cells) and cultured in Dulbecco modified Eagle medium (DMEM with high glucose, D6429, Sigma-Aldrich Sweden AB, Stockholm, Sweden) supplemented with $15 \%$ fetal bovine serum (6250, StemCell Technologies Inc., Vancouver, Canada), 2 mM L-glutamine (G7513-100 ml, SigmaAldrich Sweden AB, Stockholm, Sweden), 1 \% Penicillin and streptomycin (P4333-100 ml, Sigma-Aldrich Sweden $\mathrm{AB}$, Stockholm, Sweden), $10 \mathrm{ng} / \mathrm{ml}$ human interleukin-6 (2506, StemCell Technologies SARL, Grenoble, France), $6 \mathrm{ng} / \mathrm{ml}$ murine interleukin-3 (2733, StemCell Technologies SARL, Grenoble, France), and $50 \mathrm{ng} / \mathrm{ml}$ murine stem cell factor (2931 StemCell Technologies SARL, Grenoble, France) (complete medium). Transduction was achieved by co-culturing 5 -FU treated murine BM cells with irradiated $(2 \times 25$ Gray $)$ GP + E86 viral cells in complete medium supplemented with $5 \mu \mathrm{g} / \mathrm{ml}$ protamine sulfate (P-4020, Sigma-Aldrich Sweden AB, Stockholm, Sweden). Two days later, gentle flushing of the wells separated non-adherent BM cells from adherent viral cells. BM cells were pelleted, resuspended in fresh complete culture medium and expanded for 5 days. Selection of transduced cells was achieved by addition of $0.3 \mathrm{mg} / \mathrm{ml} \mathrm{G} 418$ disulfate salt solution (G8168-10 ml, Sigma-Aldrich Sweden AB, Stockholm, Sweden) to the culture medium followed by sorting of $\mathrm{GFP}^{+} / \mathrm{YFP}^{+}$cells on a three-laser $\mathrm{BD}$ FACSAria (405, 488 and $633 \mathrm{~nm}$ from BD Biosciences).

\section{BM transplantation of $\mathrm{C} 57 \mathrm{BL} / 6 \mathrm{~J}$ mice}

Transduced BM cells were injected into the tail vein of lethally irradiated (800 cGray) C57BL/6 J mice 1 day after FACS selection of transduced cells. Transplants consisted of 100000 to $200000 \mathrm{NPMc}^{+}$, Meis1, Hoxa9, Meis1$\mathrm{NPMc}^{+}$or Hoxa9-NPMc ${ }^{+}$cells and two million life-sparing naïve BM cells. Mice were monitored daily during the initial 2 weeks for signs of morbidity. Analyzing the percentage of $\mathrm{GFP}^{+} / \mathrm{YFP}^{+}$cells in peripheral blood, with a four-laser BDLSRFortessa $(405,488,532$ and $640 \mathrm{~nm}$ from BD Biosciences), allowed monitoring of engraftment and disease progression in real-time.

\section{Quantitative real-time PCR}

BM cells were stored in RNAprotect Cell Reagent (76526, Qiagen AB, Sollentuna, Sweden) until total RNA was extracted using the RNeasy Plus Mini kit (74136, Qiagen $A B$, Sollentuna, Sweden) and cDNA synthesized by SuperScript III First-Strand Synthesis SuperMix for qRTPCR (11752, Invitrogen, Life Technologies Europe BV, Stockholm, Sweden) all according to the manufacturer's instructions. Gene expression was analyzed by TaqMan Gene Expression Assays; hNPM1, Hs02339479_g1; hNPM1mutA, Hs00000953_mu; mHoxa9, Mm00439364_ m1; hMeis1, Hs00180020_m1; and as reference gene, mHPRT1, Mm01545399_m1 (Applied Biosystems, Life Technologies Europe BV, Stockholm, Sweden) according to the manufacturer's instructions on a ABI PRISM ${ }^{\circledR} 7900 \mathrm{HT}$ instrument (Applied Biosystems, Life Technologies Europe BV, Stockholm, Sweden). Gene expression results are presented as $2^{\wedge}$-[Ct(target)-Ct (HPRT1)]. 


\section{Sequencing}

Genomic DNA was isolated from the BM cells 21 days post transduction with the DNeasy Blood \& Tissue kit (69504, Qiagen AB, Sollentuna, Sweden). The sequence over the NPM1 mutation site was analyzed by Sanger sequencing utilizing the BigDye Terminator v3.1 Cycle Sequencing kit (4337455, Applied Biosystems, ThermoFisher Scientific, Hagersten, Sweden) on a 3130xl Genetic Analyzer.

\section{Methylcellulose colony forming assay}

Colony forming unit (CFU) assay was used to evaluate the proliferative capacity of cells after transduction with above mentioned genes. 100 to 5000 cells were seeded in methylcellulose medium (Methocult M3434, StemCell Technologies SARL, Grenoble, France). After 7 days, the number of colonies was counted and the following day cells were replated.

\section{May-Grünwald-Giemsa staining}

Using a Shandon CytoSpin 2 (Axel Johnson Instrument AB, Stockholm, Sweden), transduced BM cells were sprayed onto glass slides and allowed to air-dry. Slides were May-Grünwald-Giemsa stained and images taken on a Nikon Eclipse $90 i$ microscope.

\section{Statistics}

For statistical analyses, Student's unpaired $t$ test was performed. All statistical analyses were calculated using GraphPad Prism Version 6.0.

\section{Results}

To clarify whether NPMc ${ }^{+}$and Meis1 or Hoxa9 cooperate in induction of AML, 5-FU-treated BM cells from C57BL/6 J mice were transduced with aforementioned genes as outlined in Fig. 1a. Successfully transduced cells were FACS-sorted based on GFP and/or YFP expression

a

\begin{tabular}{|l|l|l|l|l|l|}
\hline \multirow{2}{*}{ Abbreviation } & \multicolumn{5}{|c|}{ Gene Combination } \\
\cline { 2 - 7 } & YFP or neo & GFP & Meis1-YFP & NPMc ${ }^{+}$-GFP & Hoxa9-neo \\
\hline NPMc $^{+}$cells & + & - & - & + & - \\
\hline Meis1 cells & - & + & + & - & - \\
\hline Hoxa9 cells & - & + & - & - & + \\
\hline Meis1-NPMc cells & - & - & + & + & - \\
\hline HoxA9-NPMc & - & - & - & + & + \\
\hline
\end{tabular}
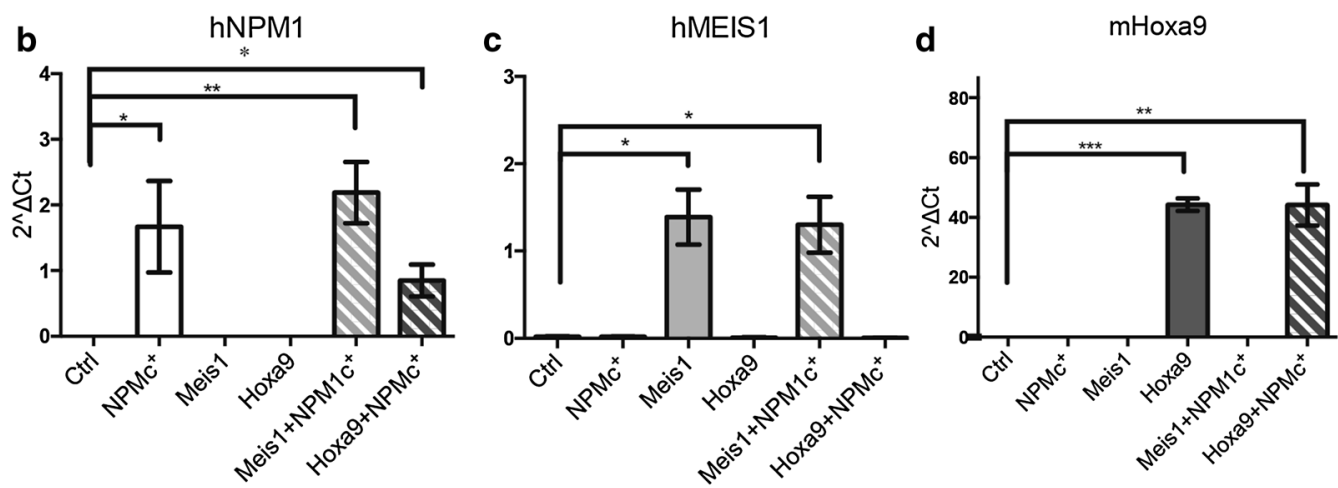

Fig. 1 Transduction of murine bone marrow cells with NPMC ${ }^{+}$, Meis1 and Hoxa9. a The table shows the combination of genes murine bone marrow cells were transduced with. b-d RNA was extracted from transduced cells using the RNeasy Plus Mini kit and analyzed by qPCR for expression of human NPM1 (b), human MEIS1 $(\mathbf{c})$ and murine Hoxa9 $(\mathbf{d})$. For all qPCR analysis $n=3$. The bars indicate mean $\pm S D$. Statistical calculations were performed using Student's unpaired t test. ${ }^{*} p<0.05,{ }^{* *} p<0.01,{ }^{* * *} p<0.001$ 
and sorted cells were utilized in the further experiments. Quantitative PCR (qPCR) analysis confirmed increased mRNA expression levels of NPMc ${ }^{+}$, Meis1 and Hoxa9 in all transduced cells (Fig. 1b-d). The presence of the correct sequence of mutated NPM1 in the transduced $\mathrm{NPMc}^{+} \mathrm{BM}$ cells was verified by sequencing. No enhancement of Hoxa9 expression was observed in the $\mathrm{NPMc}^{+}$liquid cultures (Fig. 1d).

Next, the transfected cells were analyzed by CFU assays to investigate a potential synergy between $\mathrm{NPMc}^{+}$ and Meis1 or Hoxa9 in leukemogenic transformation. Cells were cultured in methylcellulose medium for 7 days before enumeration of colonies. Cells transduced with $\mathrm{NPMc}^{+}$, Meis1 or Hoxa9 all showed enhanced serial colony-forming activity, compared with control cells transduced only with the selection markers, neo, GFP or YFP, where virtually no colonies were formed after the first replating (Fig. 2a). The colony forming capacity was highest in cells overexpressing Hoxa9 but no significant differences were observed in colony formation of single transduced cells and cells transduced to express both $\mathrm{NPMc}^{+}$and Meis1 or $\mathrm{NPMc}^{+}$and Hoxa9 (Fig. 2a). Similarly, it was noticed that only cells overexpressing Hoxa9 (in the presence or absence of $\mathrm{NPMc}^{+}$) became immortalized and survived long-term in vitro cultures.

In support of the necessity of increased Hoxa9 levels for improved proliferative capacity, May-Grünewald-Giemsa staining of cells revealed that Hoxa9 expression was required for cells to maintain a blast-like cell-morphology (Fig. 2d and f). In the absence of increased Hoxa9 expression levels, cells differentiated and mainly displayed the morphology of monocytes, macrophages and neutrophils (Fig. 2b, c and e).

Colony-forming capability in vitro often mirrors the potential of cells to engraft in mice [23]. In accordance, transplantation with $\mathrm{NPMc}^{+}$, Meis1 or Meis1-NPMc ${ }^{+}$ cells (in combination with life-sparing $\mathrm{BM}$ cells) to lethally irradiated C57BL/6 J mice did not lead to longterm engraftment, as the percentage of transfected cells in the blood of the mice was consistently below $1.5 \%$ (Fig. 2g). In contrast, transplantation with Hoxa9 and Hoxa9-NPMc ${ }^{+}$cells led to long-term engraftment of leukemic cells, albeit at a low level (Fig. 2g). Three out of five mice transplanted with Hoxa9 cells developed late onset leukemia, with the first mice progressing into leukemia displaying disease symptoms, as determined by increased white blood cell counts along with an increased frequency of $\mathrm{GFP}^{+} / \mathrm{YFP}^{+}$leukemic cells in blood, approximately 16 weeks after transplantation (Fig. $2 \mathrm{~g}$ ). None of the mice transplanted with Hoxa9-NPMc ${ }^{+}$cells showed signs of disease progression within the 20-week observation period (Fig. 2g).

\section{Discussion}

Our in vitro and in vivo results consistently demonstrate a lack of synergy between $\mathrm{NPMc}^{+}$and Meis1 or Hoxa9 in terms of transforming murine bone marrow cells and causing AML in an experimental transplantation model. Although $\mathrm{NPMc}^{+}$has been associated with enhanced Hoxa9 expression in AML patients [11] and in transduced murine BM cells [15], we did not observe enhanced expression in our $\mathrm{NPMc}^{+}$liquid cultures (Fig. 1d). The reason for absent Hoxa9 induction and for the low leukemogenic capacity of the $\mathrm{NPMc}^{+}$cells utilized in our study might be that normal levels of wild-type NPM1 was expressed by the transduced BM cells. Hence, NPM1 mutations in patients might cause disease both by causing a reduced expression of wild-type NPM1 (expression from only one allele), and by the oncogenic activity of $\mathrm{NPMc}^{+}$. NPM1 mutations are always heterozygous and a complete knock out of the protein results in embryonic lethality in mice [24]. However, mice genetically engineered to express only one wild-type NPM1 allele display a higher susceptibility to hematological malignancies, including myeloid leukemia, indicating that loss of NPM1 function is a mechanism of pathogenicity [25].

Since NPM1 mutations in AML always result in cytoplasmic localization of the protein, it is conceivable that $\mathrm{NPMc}^{+}$plays a crucial role in pathogenicity. $\mathrm{NPMc}^{+}$has been ascribed oncogenic functions [26-28] and transgenic mice expressing $\mathrm{NPMc}^{+}$within the myeloid compartment develop a myeloproliferative disease, albeit no AML [8]. To mimic the situation in human AML, conditional knock-in models, referred to as $\mathrm{Npm}^{c \mathrm{cA} /+}$ mice, have been developed where $\mathrm{NPMc}^{+}$is expressed in mice that display reduced expression-levels of wild-type NPM1. In this setting, one-third of the $N p m 1^{c A /+}$ mice developed late onset $\mathrm{AML}$, indicating a more aggressive course of disease [9].

Furthermore, when $\mathrm{NPMc}^{+}$was introduced to $\mathrm{BM}$ cells from transgenic $\mathrm{NPM}^{+/-}$mice, the increase in Hoxa9 expression was much greater than when $\mathrm{NPMc}^{+}$was introduced to wild type BM cells [15]. However, in this previous study, even $\mathrm{NPMc}^{+}$expressing $\mathrm{NPM}^{+/-}$bone marrow cells failed to cause AML when transplanted into irradiated mice, highlighting the importance of cooperative genes [15]. Thus, even in conditions of reduced wild type NPM1 expression, the selection of genes to cooperate with $\mathrm{NPMc}^{+}$in triggering AML is crucial. We and others have previously shown that Hoxa9 and Meis1 act in synergy to cause leukemia in transplantation models $[17,29]$. Since $\mathrm{NPMc}^{+}$should trigger an enhanced Hoxa9 expression on a $\mathrm{NPM} 1^{+/-}$background [15], it is conceivable that $\mathrm{NPMc}^{+}$should cooperates with Meis1 in causing AML if $\mathrm{NPM}^{+/-}$bone marrow cells would be utilized, which merits further studies. Cells overexpressing Hoxa9 
a

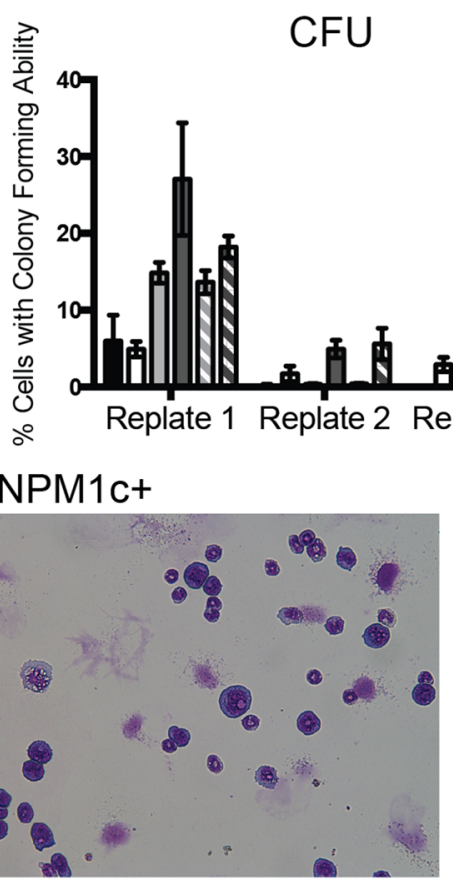

e Meis1-NPMc+

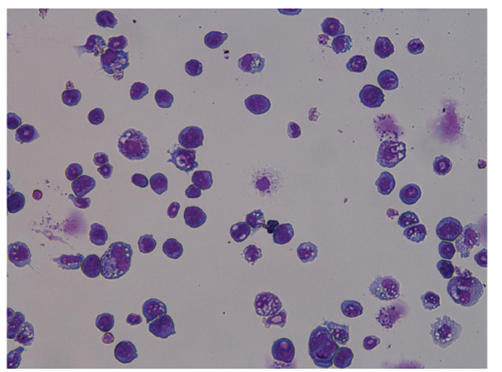

c Meis1

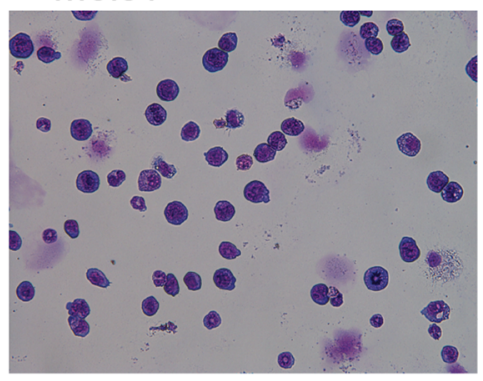

\section{f Hoxa9-NPMc+}

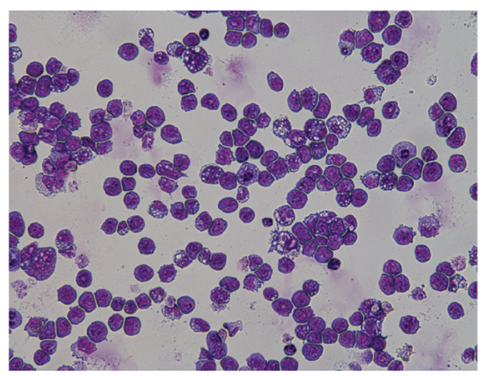

d Hoxa9

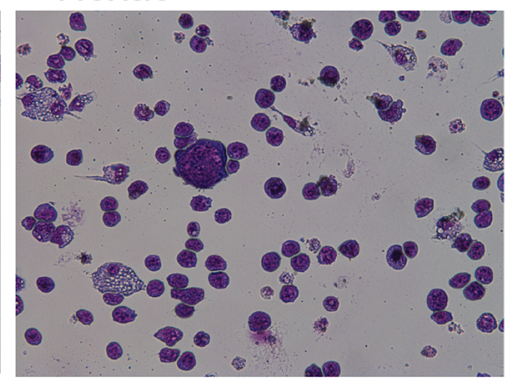

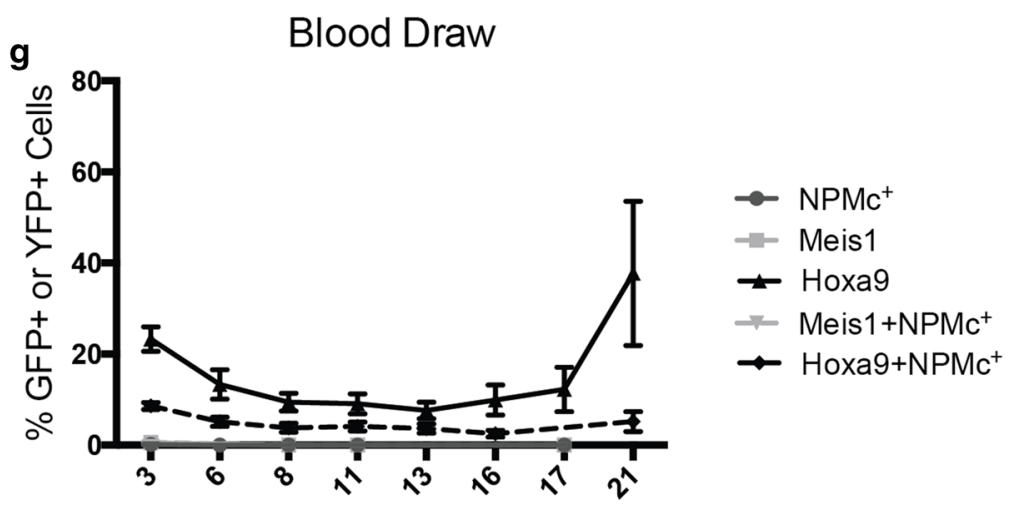

Weeks post transplantation

Fig. 2 No synergy in transforming capacity of $\mathrm{NPMC}^{+}$and Meis1 or Hoxa9. a Percentage of single and double transduced cells forming colonies on methocult plates after serial replatings: Control (empty GFP+/YFP+ vector) ( $n=4$ at replate 1 and $n=2$ at replate 2), NPMc $+(n=7$ at replate 1 and 2 and $n=5$ at replate 3$)$, Meis $1(n=3), \operatorname{Hoxa9}(n=10$ at replate 1 and $2, n=7$ at replate 3$)$, Meis $1-\mathrm{NPMc}^{+}(n=3)$, and Hoxa9-NPMc ${ }^{+}(n=4$ at replate 1 and 2 and $n=2$ at replate 3). b-f Representative images from May-Grünewald-Giemsa staining showing NPMc ${ }^{+}$cells $(\mathbf{b})$, Meis1 cells (c), Hoxa9 cells $(\mathbf{d})$, Meis1-NPMc ${ }^{+}$cells $(\mathbf{e})$ and Hoxa9-NPMc ${ }^{+}$cells $(\mathbf{f}) . \mathbf{g}$ The percentage of NPMC ${ }^{+}$, Meis1, Hoxa9, Meis1-NPMc ${ }^{+}$and Hoxa9$\mathrm{NPMc}^{+}$cells (reflected by GFP+/YFP+ expression) in peripheral blood was monitored by flow cytometry during 21 weeks. NPMc $(n=8)$, Meis 1 $(n=5)$, Hoxa9 cells $(n=5)$, Meis1-NPMc cells $(n=5)$, and Hoxa9-NPMc ${ }^{+}(n=10)$. Error bars show \pm standard error of the mean (SEM) 
showed an increased colony forming and disease causing capacity compared with cells not overexpressing Hoxa9. However, our results indicate, if anything, a reduced disease causing potential of Hoxa9-NPMc ${ }^{+}$cells compared with Hoxa9 overexpressing cells alone, which do not incite additional studies of synergy between $\mathrm{NPMc}^{+}$and Hoxa9.

\section{Abbreviations}

AML: acute myeloid leukemia; NPM1: nucleophosmin 1; NPMc ${ }^{+}$: cytoplasmic NPM1; HOX: homeobox; CFU: colony forming unit; BM: bone marrow.

\section{Authors' contributions}

HGW, LP and AM designed the study, HGW, TN and AJ performed experiments and analyzed the results, HGW, LP and AM wrote the manuscript. All authors read and approved the final manuscript.

\section{Author details}

'Sahlgrenska Cancer Center, Sahlgrenska Academy, University of Gothenburg, Gothenburg, Sweden. ${ }^{2}$ Department of Clinical Chemistry, Sahlgrenska University Hospital, Bruna Stråket 16, 41345 Gothenburg, Sweden. ${ }^{3}$ Department of Clinical Chemistry and Transfusion Medicine, Institute of Biomedicine, Sahlgrenska Academy, University of Gothenburg, Gothenburg, Sweden.

\section{Acknowledgements}

The authors would like to thank Kristoffer Hellstrand for his assistance with drafting this manuscript.

\section{Competing interests}

The authors declare that they have no competing interests.

\section{Availability of data and materials}

Data and material supporting the conclusions in this article will be made available upon request.

\section{Ethical approval}

All animal experiments were approved by the Animal Ethics Research Committee in Gothenburg (reference number 86-2014).

\section{Funding}

This study was supported by the Swedish Research Council (2012-2047), the Swedish Cancer Society (CAN2014/525), the Swedish Society for Medical Research (SSMF), the Swedish Childhood Cancer Foundation (PR2014-0125), the Swedish Society of Medicine (SLS-406151), the Swedish state via the ALF agreement (ALFGBG-436961) and (ALFGBG-431881), the Erna and Victor Hasselblad foundation, BioCARE-A National Strategic Research Program at University of Gothenburg, and the Sahlgrenska Academy at University of Gothenburg.

Received: 28 May 2016 Accepted: 2 August 2016

Published online: 11 August 2016

\section{References}

1. Kandoth C, McLellan MD, Vandin F, Ye K, Niu BF, Lu C, et al. Mutational landscape and significance across 12 major cancer types. Nature. 2013;502(7471):333

2. Falini B, Nicoletti I, Martelli MF, Mecucci C. Acute myeloid leukemia carrying cytoplasmic/mutated nucleophosmin (NPMC + AML): biologic and clinical features. Blood. 2007;109(3):874-85.

3. Federici L, Falini B. Nucleophosmin mutations in acute myeloid leukemia: a tale of protein unfolding and mislocalization. Protein Sci. 2013;22(5):545-56.
4. Falini B, Mecucci C, Tiacci E, Alcalay M, Rosati R, Pasqualucci L, et al. Cytoplasmic nucleophosmin in acute myelogenous leukemia with a normal karyotype. N Engl J Med. 2005;352(3):254-66.

5. Vardiman JW, Thiele J, Arber DA, Brunning RD, Borowitz MJ, Porwit A, et al. The 2008 revision of the World Health Organization (WHO) classification of myeloid neoplasms and acute leukemia: rationale and important changes. Blood. 2009:114(5):937-51.

6. Falini B, Martelli MP, Bolli N, Sportoletti P, Liso A, Tiacci E, et al. Acute myeloid leukemia with mutated nucleophosmin (NPM1): is it a distinct entity? Blood. 2011;117(4):1109-20.

7. Falini B, Gionfriddo I, Cecchetti F, Ballanti S, Pettirossi V, Martelli MP. Acute myeloid leukemia with mutated nucleophosmin (NPM1): any hope for a targeted therapy? Blood Rev. 2011;25(6):247-54.

8. Cheng K, Sportoletti P, Ito K, Clohessy JG, Teruya-Feldstein J, Kutok JL, et al. The cytoplasmic NPM mutant induces myeloproliferation in a transgenic mouse model. Blood. 2010;115(16):3341-5.

9. Vassiliou GS, Cooper JL, Rad R, Li J, Rice S, Uren A, et al. Mutant nucleophosmin and cooperating pathways drive leukemia initiation and progression in mice. Nat Genet. 2011;43(5):470.

10. Mallardo M, Caronno A, Pruneri G, Raviele PR, Viale A, Pelicci PG, et al. NPMC+ and FLT3_ITD mutations cooperate in inducing acute leukaemia in a novel mouse model. Leukemia. 2013;27(11):2248-51.

11. Andreeff M, Ruvolo V, Gadgil S, Zeng C, Coombes K, Chen W, et al. HOX expression patterns identify a common signature for favorable AML. Leukemia. 2008;22(11):2041-7.

12. Verhaak RGW, Goudswaard CS, van Putten W, Bijl MA, Sanders MA Hugens W, et al. Mutations in nucleophosmin (NPM1) in acute myeloid leukemia (AML): association with other gene abnormalities and previously established gene expression signatures and their favorable prognostic significance. Blood. 2005;106(12):3747-54

13. Alcalay M, Tiacci E, Bergomas R, Bigerna B, Venturini E, Minardi SP, et al. Acute myeloid leukemia bearing cytoplasmic nucleophosmin $(\mathrm{NPMC}+\mathrm{AML})$ shows a distinct gene expression profile characterized by up-regulation of genes involved in stem-cell maintenance. Blood. 2005;106(3):899-902.

14. Mullighan CG, Kennedy A, Zhou X, Radtke I, Phillips LA, Shurtleff SA, et al. Pediatric acute myeloid leukemia with NPM1 mutations is characterized by a gene expression profile with dysregulated HOX gene expression distinct from MLL-rearranged leukemias. Leukemia. 2007;21(9):2000-9.

15. Ogawara Y, Katsumoto T, Aikawa Y, Shima Y, Kagiyama Y, Soga T, et al. IDH2 and NPM1 mutations cooperate to activate Hoxa9/Meis1 and hypoxia pathways in acute myeloid leukemia. Cancer Res. 2015;75(10):2005-16.

16. Argiropoulos B, Humphries RK. Hox genes in hematopoiesis and leukemogenesis. Oncogene. 2007;26(47):6766-76.

17. Thorsteinsdottir U, Kroon E, Jerome L, Blasi F, Sauvageau G. Defining roles for HOX and MEIS1 genes in induction of acute myeloid leukemia. Mol Cell Biol. 2001;21(1):224-34

18. Staffas A, Arabanian L, Wei YS, Jansson A, Stahlman S, Johansson P, et al. Up-regulation of Flt3 is a passive event in Hoxa9/Meis1-induced acute myeloid leukemia in mice. Oncogene ONC-2015-02742R. 2016 (accepted).

19. Pineault N, Abramovich C, Humphries RK. Transplantable cell lines generated with NUP98-Hox fusion genes undergo leukemic progression by Meis1 independent of its binding to DNA. Leukemia. 2005;19(4):636-43

20. Ito T, Kwon HY, Zimdahl B, Congdon KL, Blum J, Lento WE, et al. Regulation of myeloid leukaemia by the cell-fate determinant Musashi. Nature. 2010:466(7307):765-8.

21. Morgado E, Albouhair S, Lavau C. Flt3 is dispensable to the Hoxa9/Meis1 leukemogenic cooperation. Blood. 2007;109(9):4020-2.

22. Palmqvist L, Argiropoulos B, Pineault N, Abramovich C, Sly LM, Krystal $\mathrm{G}$, et al. The Flt3 receptor tyrosine kinase collaborates with NUP98-HOX fusions in acute myeloid leukemia. Blood. 2006;108(3):1030-6.

23. Somervaille TCP, Cleary ML. Identification and characterization of leukemia stem cells in murine MLL-AF9 acute myeloid leukemia. Cancer Cell. 2006;10(4):257-68.

24. Grisendi S, Bernardi R, Rossi M, Cheng K, Khandker L, Manova K, et al. Role of nucleophosmin in embryonic development and tumorigenesis. Nature 2005:437(7055):147-53. 
25. Sportoletti P, Grisendi S, Majid SM, Cheng K, Clohessy JG, Viale A, et al. $\mathrm{Npm} 1$ is a haploinsufficient suppressor of myeloid and lymphoid malignancies in the mouse. Blood. 2008;111(7):3859-62.

26. Cheng K, Grisendi S, Clohessy JG, Majid S, Bernardi R, Sportoletti P, et al. The leukemia-associated cytoplasmic nucleophosmin mutant is an oncogene with paradoxical functions: arf inactivation and induction of cellular senescence. Oncogene. 2007;26(53):7391-400.

27. Bonetti P, Davoli T, Sironi C, Amati B, Pelicci PG, Colombo E. Nucleophosmin and its $\mathrm{AML}$-associated mutant regulate c-Myc turnover through Fbw7 gamma. J Cell Biol. 2008;182(1):19-26.
28. Leong SM, Tan BX, Ahmad BB, Yan T, Chee LY, Ang ST, et al. Mutant nucleophosmin deregulates cell death and myeloid differentiation through excessive caspase-6 and-8 inhibition. Blood. 2010;116(17):3286-96.

29. Kroon E, Krosl J, Thorsteinsdottir U, Baban S, Buchberg AM, Sauvageau G. Hoxa9 transforms primary bone marrow cells through specific collaboration with Meis1a but not Pbx1b. EMBO J. 1998;17(13):3714-25.

\section{Submit your next manuscript to BioMed Central and we will help you at every step:}

- We accept pre-submission inquiries

- Our selector tool helps you to find the most relevant journal

- We provide round the clock customer support

- Convenient online submission

- Thorough peer review

- Inclusion in PubMed and all major indexing services

- Maximum visibility for your research

Submit your manuscript at

www.biomedcentral.com/submit 